\title{
Menopausal symptoms in rural middle aged women: a community based cross sectional study
}

\author{
Najma Akhtar*, Rajiv K. Gupta, Kiran Bala, Vijay Mengi, Chandni Gupta
}

Department of Community Medicine, Government Medical College, Jammu, Jammu and Kashmir, India

Received: 26 June 2018

Accepted: 26 July 2018

\section{*Correspondence:}

Dr. Najma Akhtar,

E-mail: najmaakhtar907@gmail.com

Copyright: (C) the author(s), publisher and licensee Medip Academy. This is an open-access article distributed under the terms of the Creative Commons Attribution Non-Commercial License, which permits unrestricted non-commercial use, distribution, and reproduction in any medium, provided the original work is properly cited.

\begin{abstract}
Background: Menopause poses a big challenge to the healthy aging of a woman. With growing emphasis on universal health coverage and improving quality of life, it is the need of hour to address the issues population of postmenopausal women to enhance our understanding of women's experiences during menopause.

Methods: This cross-sectional study was conducted using non-probability purposive sampling and house-to-house visit in randomly selected villages falling under rural Health Block Kot-Bhalwal. 245 postmenopausal women were interviewed in accordance with pretested questionnaire consisting of Sociodemographic data and Greene Climacteric Scale.

Results: Muscle and joint pains was the most common complaint (89.0\%), followed by feeling tired or lacking in energy $(87.4 \%)$, difficulty in sleeping $(82.5 \%)$ and difficulty in concentrating $(80.4 \%)$. Nearly three-fourth of the study participants reported to be suffering from Irritability (77.6\%), feeling tense/nervous (77.5\%), Headaches (76.7\%), loss of interest in most things $(75.9 \%)$, feeling unhappy or depressed $(74.29 \%)$, sweating at night $(73.47 \%)$, attacks of anxiety, panic (73.5\%), pressure or tightness in head (72.6\%), and feeling dizzy or faint (71.8\%).

Conclusions: A higher prevalence of menopausal symptoms was found. However, more research studies are needed to determine rural urban differences in prevalence and severity of the symptoms using a standardized tool on a larger sample in the community setting.
\end{abstract}

Keywords: Greene Climacteric Scale, Menopause, Rural women

\section{INTRODUCTION}

Menopause is a physiological transition from reproductive to nonreproductive stage. ${ }^{1}$ It directly or indirectly has a effect on the wellbeing of middle aged woman and lower her quality of life. Demographic transition, increasing advancement in medical sciences and changing life expectancy has made it of utmost importance to understand this transition for fulfilling health needs and concerns of postmenopausal population.

It is stated that about two hundred years ago, only $30 \%$ of women lived through menopause. Thus, the menopause transition and post menopause are very much a condition of the $20^{\text {th }}$ and $21^{\text {st }}$ centuries. ${ }^{2}$ In India, about 12.6 million women are above 45 years of age, thus contributing to about $10.4 \%$ of the total population. ${ }^{3}$ Today's woman will live one-third of her life after menopause. ${ }^{4}$

Every woman's experience of the menopause is unique; she may experience all of the symptoms or none. Some find the transition barely noticeable, while others find it as life altering. ${ }^{5}$

Over $85 \%$ of all women are reported to suffer from at least one menopausal symptom during transition through 
menopause. ${ }^{6}$ Menopause symptoms include vasomotor symptoms (hot flushes, night sweats, insomnia), urogenital symptoms (urgency, stress incontinence, nocturia, dysuria, vaginal dryness, dyspareunia), mood changes (anxiety, irritability and depression), cognitive disturbances (forgetfulness, lack of concentration), somatic symptoms( joint pain, backache and headaches) and many others symptoms like weight gain, palpitations, crying spells, lack of energy and dizzy spells. $^{7-9}$

Moreover, post-menopausal woman becomes more prone to certain diseases like osteoporosis, CVS diseases, cancer and decrease in cognitive functions. ${ }^{7,9}$

Menopause is multidimensional and has impact on women's physiological, physical, psychological and mental health. Numerous factors that determine women's experience towards menopause include ethnicity, culture, social background, menopausal status, attitude, education, diet, genetics, occupation and overall health. ${ }^{10-16}$

There is little data available on this aspect of menopause in women from Indian subcontinent, especially Northern India. The purpose of this research was to enhance our understanding of menopausal experiences of postmenopausal woman in a rural setting.

\section{METHODS}

This cross-sectional study was conducted from November 2015 to October 2016 in rural villages falling under Block Kot Bhalwal which is situated at a distance of 10 km from Government Medical College, Jammu, having population of approx. 1 lakh 40 thousand spreading over 107 villages. Majority of the population comprises of Hindus and Muslims, with agriculture as the main source of livelihood.

\section{Inclusion criteria}

Women who had attained menopause and were willing to participate in the study by giving their written informed consent were included in the study.

\section{Exclusion criteria}

- Women with induced menopause, seriously ill women due to causes not associated with menopause

- And those who did not agree to participate in the study.

\section{Method of sampling and data collection}

After seeking ethical approval from Institutional Ethical Committee, Government Medical College, Jammu, the investigator met the Block Medical Officer and other health staff; briefed them about the study and enlisted their support. One village was randomly selected from the list of villages covered under Health Block KotBhalwal. Thereafter, using non-probability purposive sampling, all eligible candidates were covered as far as possible by house-to-house visit. After the completion of the survey of selected village, second village was chosen again randomly and covered. In this manner, a total of 4 villages were surveyed by the research investigator during the course of current study.

At the time of the interview, informed written consent was taken from eligible participants after briefing them about the purpose of study.

Thereafter, interview was conducted in accordance with pretested semi-structured questionnaire. In order to take care of the situational contaminants, women were interviewed in a calm and private place at their respective homes or farms during harvesting season.

\section{Tool for research}

The instrument designed for the present study consists of Sociodemographic data and Greene Climacteric Scale (GCS).

Greene Climacteric Scale (GCS) 17 is a validated menopausal symptom scale which is used routinely in clinical practice as a research tool. The Greene's Climacteric Scale scores the severity of 21 symptoms on 4-point Likert scale which ranges from 0 (not at all) to 3(extremely) and further divides these symptoms into 4 sub scales-psychological score (11 symptoms), somatic score ( 7 symptoms), vasomotor score (2 symptoms) and sexual score (1 symptom).

The psychological subscale is further divided into Anxiety (6 symptoms), and Depression (5 symptoms). The Cronbach's alpha reliability of this scale for the current study was 0.77 .

\section{Statistical analysis}

The data so collected was first entered into a master chart on Microsoft Excel spreadsheet for descriptive statistics, data was grouped, tabulated and represented as means with standard deviation and percentages for quantitative variables and qualitative variables respectively.

\section{RESULTS}

Majority of the postmenopausal women of the study population were in the age group 50-59 years (40.8\%) followed by age group 60-69 years $(30.6 \%)$. Five of the study participants $(2.5 \%)$ entered menopause prematurely.

Most of the participants $(53.3 \%)$ belonged to Muslims religion followed by Hindu religion $(46.9 \%)$. More than $80 \%$ of the women in our study were married, while 
widows (14.7\%), divorced/separated (1.6\%) and unmarried $(0.4 \%)$ comprised the rest. About $63 \%$ women were illiterate while women with education up to the middle school comprised $29.8 \%$ of the total. Majority of the respondents $(90 \%)$ were housewives.

As far as the occupation of the husbands was concerned, half $(51 \%)$ of them belonged to labour class, mostly farmers. The monthly income of one third (67.7\%) of the participants was less than Rs.5000 from all sources and further 77 postmenopausal women in this group reported monthly income less than Rs. 1000.

More than two-third of the respondents (69\%) were nonsmokers. Among the current smokers, majority were hookah smokers $(67.1 \%)$ and biddi smokers (29\%) (Table $1)$.

Table 1: Socio demographic profile of the study participants.

\begin{tabular}{|c|c|c|}
\hline Variable & Category & $\begin{array}{l}\text { No. of } \\
\text { postmenopausal } \\
\text { women }(\%)\end{array}$ \\
\hline \multirow{5}{*}{$\begin{array}{l}\text { Age groups } \\
\text { (in years) }\end{array}$} & $<40^{*}$ & $5(2.1)$ \\
\hline & $40-49$ & $49(20)$ \\
\hline & $50-59$ & $100(40.8)$ \\
\hline & $60-69$ & $75(30.6)$ \\
\hline & $\geq 70$ & $16(6.5)$ \\
\hline \multirow[t]{3}{*}{ Religion } & Hindu & $115(46.9)$ \\
\hline & Muslim & $128(52.3)$ \\
\hline & Others* & $2(0.8)$ \\
\hline \multirow{4}{*}{$\begin{array}{l}\text { Marital } \\
\text { status }\end{array}$} & Married & $204(83.3)$ \\
\hline & Unmarried & $1(0.4)$ \\
\hline & Divorced/separated & $4(1.6)$ \\
\hline & Widow & $36(14.7)$ \\
\hline \multirow{4}{*}{ Education } & Illiterate & $154(62.9)$ \\
\hline & Up to middle & $73(29.8)$ \\
\hline & Up to Hr. secondary & $16(6.5)$ \\
\hline & $\begin{array}{l}\text { Higher education } \\
\text { /degree }\end{array}$ & $2(0.8)$ \\
\hline \multirow{2}{*}{$\begin{array}{l}\text { Employment } \\
\text { status }\end{array}$} & Employee & $15(6.1)$ \\
\hline & House wife & $230(93.9)$ \\
\hline \multirow{4}{*}{$\begin{array}{l}\text { Occupation } \\
\text { of husband }\end{array}$} & Labour & $125(51.0)$ \\
\hline & Service & $47(19.2)$ \\
\hline & Business & $25(10.2)$ \\
\hline & No work* & $7(2.8)$ \\
\hline \multirow{5}{*}{$\begin{array}{l}\text { Monthly } \\
\text { family } \\
\text { income (in } \\
\text { rupees) }\end{array}$} & $<5000$ & $166(67.7)$ \\
\hline & $5001-10000$ & $37(15.1)$ \\
\hline & $10001-15000$ & $7(2.9)$ \\
\hline & $15001-20000$ & $10(4.1)$ \\
\hline & $>20000$ & $25(10.2)$ \\
\hline \multirow{3}{*}{$\begin{array}{l}\text { Smoking } \\
\text { status }\end{array}$} & Non-smoker & $169(69.0)$ \\
\hline & Past smoker & $28(11.4)$ \\
\hline & Current smoker & $48(19.6)$ \\
\hline
\end{tabular}

$*$ Premature menopause; $\ddagger$ Mean Age $\pm \mathrm{SD}=56.49 \pm 9.9$ years , Median $=56$ years $($ Range $=36$ to 106 years $)$

More than $70 \%$ of the women were having three to five living children. Only four women in our study were not having any living children. Most of the study participants $(\geq 80 \%$ ) reported attaining menarche between the age of 11 to 15 years. Only 1 woman reported to have menarche before age of 10 years while $42(17.2 \%)$ attained it after 16 years of age. Nearly $80 \%$ of the study participants had attained menopause by the age of 50 years of which $14.3 \%$ women reported menopause prematurely i.e. before 40 years of age (Table 2).

In the current study, Muscle and joint pains was reported as the most prevalent $(89.0 \%)$, symptoms followed by feeling tired or lacking in energy $(87.4 \%)$, difficulty in sleeping $(82.5 \%)$ and difficulty in concentrating $(80.4 \%)$. Nearly three-fourth of the study participants reported to be suffering from irritability $(77.6 \%)$, feeling tense/nervous $(77.5 \%)$, headaches $(76.7 \%)$, loss of interest in most things $(75.9 \%)$, feeling unhappy or depressed (74.29\%), sweating at night (73.47\%), attacks of anxiety, panic $(73.5 \%)$, pressure or tightness in head $(72.6 \%)$, and feeling dizzy or faint $(71.8 \%)$.

More than half of participants reported to be experiencing excitable $(68.6 \%)$ crying spells $(64.90 \%)$, hot flushes $(62.0 \%)$, loss of feeling in hands or feet $(62.0 \%)$ Parts of body feel numb (62.0\%) loss of interest in sex $(61.2 \%)$ and heart beating quickly/strongly $(55.9 \%)$. The least reported symptom as per GCS was breathing difficulties $(45.3 \%)$ (Table 3).

The mean total Greene score for the 21 items were 31.74 $(\mathrm{SD} \pm 10.39)$. Somatic cluster had the highest mean score (9.95 SD \pm 4.2 ) among the four domains following psychological domain in which sub-cluster anxiety and depression scored somewhat similar i.e. 8.93( \pm 4.10$)$ and 8.13(SD \pm 3.44$)$, although anxiety mean scores was slightly high (Table 4).

Most of the study participants reported to have experienced backache and memory problems $(80.4 \%$ and $69.4 \%$ respectively). Out of 196 participants who were married, staying with their husbands and reported themselves to be sexually active, only 58 women reported having pain during intercourse (Table 5).

Table 2: Distribution of the participants as per gynaecological profile.

\begin{tabular}{|lll|}
\hline Variables & Category & Frequency $(\%)$ \\
\hline Age at menarche & $\leq 10$ & $1(0.4)$ \\
& $11-15$ & $202(82.4)$ \\
& $16-20$ & $42(17.2)$ \\
\hline \multirow{2}{*}{$\begin{array}{l}\text { Age at } \\
\text { menopause }\end{array}$} & $31-40$ & $35(14.3)$ \\
& $41-50$ & $181(68.2)$ \\
\hline \multirow{2}{*}{$\begin{array}{l}\text { No. of living } \\
\text { children }\end{array}$} & $51-60$ & $28(17.1)$ \\
\hline & $>60$ & $1(0.4)$ \\
\hline & nil & $4(1.6)$ \\
\hline
\end{tabular}


Table 3: Distribution of study respondents according to Greene climacteric scale scores and percentages per symptom.

\begin{tabular}{|c|c|c|c|c|}
\hline \multirow{3}{*}{ SYMPTOMS REPORTED } & \multicolumn{4}{|c|}{ FREQUENCY } \\
\hline & Nil & Mild & Moderate & Severe \\
\hline & $\mathrm{N}(\%)^{*}$ & $\mathrm{~N}(\%)^{*}$ & $\mathrm{~N}(\%)^{*}$ & $\mathrm{~N}(\%)^{*}$ \\
\hline Heart beating quickly or strongly & $108(44.1)$ & $54(22.0)$ & $57(23.3)$ & $26(10.6)$ \\
\hline Feeling tense or nervous & $56(22.9)$ & $40(16.3)$ & $103(42.0)$ & $46(18.6)$ \\
\hline Difficulty in sleeping & $43(17.6)$ & $38(15.5)$ & $73(29.8)$ & $91(37.1)$ \\
\hline Excitable & $77(31.4)$ & $74(30.2)$ & $60(24.5)$ & $34(13.9)$ \\
\hline Attacks of anxiety, panic & $65(26.5)$ & $33(13.5)$ & $89(36.3)$ & $58(23.7)$ \\
\hline Difficulty in concentrating & $48(19.6)$ & $59(24.1)$ & $54(22.0)$ & $84(34.3)$ \\
\hline Feeling tired or lacking in energy & $31(12.7)$ & $31(12.7)$ & $74(30.2)$ & $109(44.5)$ \\
\hline Loss of interest in most things & $59(24.1)$ & $55(22.5)$ & $84(34.3)$ & $47(19.2)$ \\
\hline Feeling unhappy or depressed & $63(25.7)$ & $43(17.6)$ & $74(30.2)$ & $65(26.5)$ \\
\hline Crying spells & $86(35.1)$ & $37(15.1)$ & $70(28.6)$ & $52(21.2)$ \\
\hline Irritability & $55(22.5)$ & $46(18.8)$ & $75(30.6)$ & $69(28.2)$ \\
\hline Feeling dizzy or faint & $69(28.2)$ & $57(23.3)$ & $79(32.2)$ & $40(16.3)$ \\
\hline Pressure or tightness in head & $67(27.5)$ & $48(19.6)$ & $73(29.8)$ & $57(23.3)$ \\
\hline Parts of body feel numb & $91(37.6)$ & $36(15.0)$ & $63(25.8)$ & $53(21.7)$ \\
\hline Headaches & $57(23.3)$ & $52(21.2)$ & $73(29.8)$ & $63(25.7)$ \\
\hline Muscle and joint pains & $27(11.0)$ & $27(11.0)$ & $59(24.1)$ & $132(53.9)$ \\
\hline Loss of feeling in hands or feet & $89(36.3)$ & $61(24.9)$ & $52(21.2)$ & $43(17.6)$ \\
\hline Breathing difficulties & $134(54.7)$ & $60(24.5)$ & $29(11.8)$ & $22(9.0)$ \\
\hline Hot flushes & $93(38)$ & $39(15.9)$ & $50(20.4)$ & $63(25.7)$ \\
\hline Sweating at night & $65(26.5)$ & $49(20)$ & $73(29.8)$ & $58(23.7)$ \\
\hline Loss of interest in sex & $49(24.62)$ & $24(12.06)$ & $41(20.6)$ & $85(42.7)$ \\
\hline
\end{tabular}

*Figures in paranthesis are percentages.

Table 4: Distribution of the score of the subscales and total Greene Climacteric score of the study respondents.

\begin{tabular}{|ll|}
\hline Dimension (no. of items) & Mean \pm SD \\
\hline Psychological (11) & $17.06( \pm 6.57)$ \\
\hline Anxiety (6) & $8.93( \pm 4.10)$ \\
\hline Depression (5) & $8.13( \pm 3.44)$ \\
\hline Somatic (7) & $9.95( \pm 4.21)$ \\
\hline Vasomotor (2) & $2.84( \pm 2.00)$ \\
\hline Sexual dysfunction $(1) *$ & $1.18( \pm 1.12)$ \\
\hline Total GCS score* & $31.75( \pm 10.39)$ \\
\hline *mean score was calculated for only 199 women (while N=245 \\
$\begin{array}{l}\text { for rest cases), excluding women with marital status as widows, } \\
\text { divorced, separated or unmarried, and age above } 70 .\end{array}$
\end{tabular}

Table 5: Distribution of various other menopausal symptoms experienced and reported by study subjects.

\begin{tabular}{|c|c|c|}
\hline \multirow{2}{*}{$\begin{array}{l}\text { Symptom reported by } \\
\text { respondants }\end{array}$} & \multicolumn{2}{|l|}{ Response } \\
\hline & Yes $(\%)$ & No $(\%)$ \\
\hline $\begin{array}{l}\text { Pain during intercourse } \\
(\mathrm{n}=196)^{*}\end{array}$ & $58(29.6)$ & $138(70.4)$ \\
\hline Vaginal dryness $(n=245)$ & $16(6.5)$ & $229(93.6)$ \\
\hline Backache $(n=245)$ & $197(80.4)$ & $48(19.6)$ \\
\hline Urinary problems $(n=245)$ & $46(18.8)$ & $199(81.2)$ \\
\hline Memory problems $(n=245)$ & $170(69.4)$ & $75(30.6)$ \\
\hline
\end{tabular}

\section{DISCUSSION}

Menopause poses a big challenge to the healthy aging of a woman. Majority of the women suffer from one or the other symptom associated with menopause. ${ }^{18}$ With the increase in life expectancy, population in the elder ages is showing an upward trend, due to which various concerns associated with the health of elderly people are emerging. Therefore, it is time to shift the focus of policy makers and healthcare managers to address the rising health issues of middle aged women and to fill the know-do gap. The present community based cross-sectional study is an attempt to find out ground reality of the menopausal experiences and understanding of rural women.

The mean age in years of the postmenopausal women in the current study was $56.49 \pm 9.9$ which was similar to that reported by Sharma et al, Pathak et al and Chuni et al. ${ }^{19-21}$ However, it was higher than that reported by Nayak et al,but lower than that reported by Christian et al and Madhukumar et al. ${ }^{22-24}$

The mean age at menopause of the participants in our study was $45.64 \pm 4.58$ yrs which was in agreement with those reported by Bagga et al, Mahajan et al, Sarker et al, Sharma et al and Satpathy. ${ }^{25-29}$ However, the mean age scores reported by the current study were lower in comparison to those reported by Sharma S et al,Christian et al, Borker et al and Madhukumar et al. ${ }^{19,23,24,30}$ 
The proportion of women who entered menopause prematurely was found to be quite high in current study. The results were in agreement to those reported by Lal and Sharma et al. ${ }^{28,31}$

The important factors responsible for the diversity in attainment of menopause include regional variation, genetic, environment and nutrition. ${ }^{29}$ However, the role of recall bias and absence of evidence in determining correct age of participants might have influenced this proportion in a detrimental way despite of investigator's best efforts to find out real age of the participants by correlating it with major events.

In the current study, the women reported muscle and joint pains as the most prevalent symptoms $(89.0 \%)$, followed by feeling of tiredness or lacking in energy $(87.4 \%)$, difficulty in sleeping $(82.5 \%)$, difficulty in concentrating $(80.4 \%)$ and backache $(80 \%)$. These results are in congruence with those reported by Subrahmanyam et al and Rahman et al. ${ }^{1,32}$ However, different studies conducted in Indian subcontinent have results suggestive of varied experiences of symptoms among the respondents. . $^{61,24,28-30,32-38}$

The possible explanation for this difference in prevalence and severity of menopausal symptoms reported may be due the social, economic demographic, cultural, health, genetic and racial differences, besides woman's attitude and awareness. ${ }^{29}$

Since more than $70 \%$ of the participants in current study were above 50 years of age, it could possibly be the reason behind the higher prevalence of somatic symptoms like muscle and joint pains, etc. in the study population. However, another important perspective which can explain this varied prevalence of symptoms is the difference in study design, study settings, sample size, menopausal status of respondents and the tools used in different studies.

\section{Limitations of the study}

Since the current study was a cross sectional one, it has inherent limitations regarding generalizability of the results. Also, Greene Climacteric scale and Modified Attitude toward Menopause are self-administered scale but were used for interviewing women keeping in view the low literacy rates of this age group population. Another limitation of the current study could be absences of comparison between premenopausal, perimenopausal and postmenopausal in women. Further, recall bias, confounding effects of ageing was another limitation.

\section{CONCLUSION}

A high prevalence of menopausal symptoms among middle aged rural women was found in this study. This research offers a preliminary groundwork for further planning and designing of evidence-based research in the field of postmenopausal health, particularly in rural setting.

Funding: No funding sources

Conflict of interest: None declared

Ethical approval: The study was approved by the Institutional Ethics Committee

\section{REFERENCES}

1. Subrahmanyam N, Padmaja A. Menopause Related Problems among Women in a Rural Community of Kerala. Int J Innovative Res Dev.2016;5(1):60-4

2. Panay N. Menopause and the postmenopausal women. In: Edmonds DK, editor. Dewhurts' textbook of obstetrics and gynecology. $7^{\text {th }}$ ed. 2007. London.

3. Govt. of India. Census 2011. Office of the Registrar General and Census Commissioner India, Ministry of Home Affairs. New Delhi; 2012. Available at: http://www.censusindia.gov.in/2011census/Cseries/c-13/DDW-0000C-13.xls (Last assessed on 25 Sept. 2016)

4. Puri S, Bhatia V, Mangat C. Perceptions of menopause and postmenopausal bleeding in women of Chandigarh, India. Internet $\mathbf{J}$ Fam Pract. 2007;6(2):1-6.

5. Avin Alva BR, Chethan TK. A study to assess the average age of menopause and menopause associated symptoms among rural women in Mangalore, Karnataka. Ntl J Community Med. 2016;7(5):404-8.

6. Vijayalakshmi S, Ramesh C, Eilean VL. Menopausal transition among northern Indian women. Nitte Univ J Health Sci. 2013;3(2):73-9.

7. Shaw RW, Patrick W, Stanton SL. Gynaecology. $2^{\text {nd }}$ edition. Churchill Livingstone. 1997.373-83.

8. World Health Organization. Research on the menopause in the 1990s: Report of a WHO Scientific Group. World Health Organ Tech Rep Ser Geneva. 1996;866:1-107.

9. Shifren JL, Schiff I. Menopause. In: Berek JS (ed.). Berek and Novak's Gynecology. 15 $5^{\text {th }}$ ed. Philadelphia: Lippincott Williams and Wilkins. 2012:1233-49.

10. Avis NE, McKinlay SM. A longitudinal analysis of women's attitudes toward the menopause: results from the Massachusetts Women's Health Study. Maturitas. 1991 Mar 1;13(1):65-79.

11. Huffman SB, Myers JE, Tingle LR, Bond LA. Menopause symptoms and attitudes of AfricanAmerican women: closing the knowledge gap and expanding opportunities for counselor. J Counselling Dev. 2005;83(1):48-56.

12. Thomas SE. Menopause knowledge and attitudes of English-speaking Caribbean women: Implications for health education. Californian J Health Promotion. 2005;3(3):167-76.

13. Nosek M, Kennedy H, Lee K. The effects of perceived stress and attitudes toward menopause and aging on symptoms of menopause. J Midwifery Women's Health. 2010;55(4):328-34. 
14. Tsehay DS, Mulatie MM, Sellakumar GK. Determinants of menopausal symptoms and attitude among middle aged women: the case of Dangila Town, North West Ethiopia. Innovare J Social Sci. 2014:2(1);15-20.

15. Huffman SB, Myers JE. Counseling women in midlife: an integrative approach to menopause. J Counseling Develop. 1999 Jul;77(3):258-66.

16. Theisen SC, Mansfield PK, Seery BL, Voda A. Predictors of midlife women's attitudes towards menopause. Health Values. 1995;19(3):22-31.

17. Vasconcelos-Raposo J, Coelhoa E, Fernandes HM, Rodrigues C, Moreiraa H, Teixeira C. Factor structure and normative data of the Greene Climacteric Scale among postmenopausal Portuguese women Maturitas. 2012;72:256-62.

18. Govil D. Health needs of middle aged population: an unaddressed link. Paper presented at: European population conference; poster session 2. 2010 Sep 14; Vienna, Austria.

19. Sharma S, Tandon VR, Mahajan A. Menopausal symptoms in urban women. Alcohol. 2007;4:3-41.

20. Pathak RK, Parashar P. Age at menopause and associated bio-social factors of health in Punjabi women. Open Anthropol J. 2010;3:172-80.

21. Chuni N, Sreeramareddy CT. Frequency of symptoms, determinants of severe symptoms, validity of and cut-off score for Menopause Rating Scale (MRS) as a screening tool: a cross-sectional survey among midlife Nepalese women. BMC Women's Health. 2011;11:30-8.

22. Nayak G, Kamath A, Kumar P, Rao A. A study of quality of life among perimenopausal women in selected coastal areas of Karnataka, India. J Midlife Health. 2012;3(2):71-5.

23. Christian D, Kathad M, Bhavsar B. Sociodemographic characteristics of postmenopausal women of rural area of Vadodara district, Gujarat. Nat J Comm Med. 2011;2(3):41922.

24. Madhukumar S, Gaikwad V, Sudeepa D. A community-based study on perceptions about menopausal symptoms and quality of life of post menopausal women in Bangalore rural. Inter J Health Sci Res. 2012;2(3):49-56.

25. Bagga A. Age and symptomatology of menopause, A case study. Obstet and Gynecol Today. 2004;11(10): 660-6.

26. Mahajan N, Aggarwal M, Bagga A. Health issues of menopausal women in North India. J Mid-life Health. 2012 Jul;3(2):84-7.

27. Sarkar A, Pithadia P, Goswami K, Bhavsar S, Makwana NR, Yadav S et al. A study on health profile of post-menopausal women in Jamnagar district, Gujarat. J Res Med Den Sci. 2014;2(2):25-9.

28. Sharma S, Mahajan N. Menopausal symptoms and its effect on quality of life in urban versus rural women: a cross-sectional study. J Mid-life Health. 2015 Jan;6(1):16-20.

29. Satpathy MA. Study on age at menopause, menopausal symptoms and problems among urban women from Western Odisha, India. Int J Sci Res Publications. 2016 March;6(3):422-7.

30. Borker SA, Venugopalan PP, Bhat SN. Study of menopausal symptoms and perceptions about menopause among women at a rural community in Kerala. J Midlife Health. 2013 Jul;4(3):182-7.

31. Lal N. Premature menopause risks rising: study. India Together 2014 (January 1), Oorvani Media Pvt. Ltd. 2007

32. Rahman S, Salehin F, Iqbal A. Menopausal symptoms assessment among middle age women in Kushtia, Bangladesh. BMC Res Notes. 2011 Dec;4(1):188.

33. Adhi M, Hasan R, Shoaib S, Tauheed S. Age and symptomatology of menopause in Karachi, Pakistan. Pak J Physiol. 2007;3(1):41-4.

34. Sagdeo MM, Arora D. Menopausal symptoms: a comparative study in rural and urban women. JK Sci. 2011;13(1):23-7.

35. Chattha R, Kulkarni R, Nagarathna R, Nagendra HR. Factor analysis of Greene's Climacteric Scale for Indian women. Maturitas. 2008 Jan 20;59(1):22-7.

36. Christian D, Kathad MM, Bhavsar BS. A clinicoepidemiological study on health problems of postmenopausal women in rural area of Vadodara district, Gujarat. Natl J of Med Res. 2012;2(4):47880.

37. Li L, Wu J, Pu D, Zhao Y, Wan C, Sun L et al. Factors associated with the age of natural menopause and menopausal symptoms in Chinese women. Maturitas. 2012;73(4):354-60.

38. Joshi M, Nair S. Epidemiological study to assess the menopausal problems during menopausal transition in middle age women of Vadodara, Gujarat, India. Indian J Obstet Gynaecol Res. 2015;2(3):163-8.

Cite this article as: Akhtar N, Gupta RK, Bala K, Mengi V, Gupta C. Menopausal symptoms in rural middle aged women: a community based cross sectional study. Int J Reprod Contracept Obstet Gynecol 2018;7:3678-83. 